Protokół rehabilitacyjny w przypadku „,kolana biegacza" (zespół pasma biodrowo-piszczeglowego) - studium przypadku

\title{
Rehabilitation protocol of „,runner's knee” (Iliotibial Band Syndrome - ITBS) - a case study
}

\author{
Ryszard Biernat, Dariusz Czaprowski
}

Olsztyńska Szkoła Wyższa im. J. Rusieckiego w Olsztynie, Wydział Fizjoterapii

\section{Streszczenie}

Wstęp: „Kolano biegacza”, inaczej zespół pasma biodrowo-piszczelowego (ang. Iliotibial Band Syndrome - ITBS) jest druga, po PFPS, pod względem częstotliwości występowania kontuzją przeciążeniową wśród biegaczy - 8.5\%. Jest najczęstszym powodem bólu bocznego przedziału kolana. Występuje u zawodników w średnim wieku, w drugiej dekadzie życia. Kolarze, narciarze, ciężarowcy, piłkarze nożni, tenisiści to kolejne grupy sportowców, u których notuje się występowanie tej jednostki. Zespół pasma biodrowo-piszczelowego jest typową kontuzją przeciążeniowa, wynikającą z cyklicznego tarcia (lub kompresji) pasma biodrowo-piszczelowego o nadkłykieć boczny kości udowej. Błędy treningowe są podstawowym czynnikiem ryzyka. Zaburzenia biomechaniczne prowadzące do powstania tej jednostki to: osłabienie mięśnia pośladkowego średniego, ograniczenie funkcjonalnej ruchomości w stawie biodrowym, osłabienie mięśni zginających i prostujących w stawie kolanowym, przykurcz mięśni przywodzących w stawie biodrowym, przykurcz rotacji wewnętrznej w stawie biodrowym. U kolarzy, ITBS może wynikać z nieprawidłowego ustawienia wysokości siodełka, niewłaściwie dobranego rozmiaru ramy lub nieprawidłowej pozycji pedałów.

Studium przypadku: Do Centrum Rehabilitacji Ruchowej zgłosił się zawodnik, czynnie uprawiający kolarstwo, skarżący się na ból w bocznej okolicy stawu kolanowego prawego. Ból trwał od 4 miesięcy. Chory opisywał go jako uporczywy, piekący, narastający podczas intensywnej jazdy na rowerze, w efekcie końcowym uniemożliwiający kontynuowanie aktywności fizycznej. Po analizie występujących zaburzeń biomechanicznych zastosowano funkcjonalny trening reedukacji, mający na celu korektę zaburzeń, będących powodem powstania zespołu pasma biodrowo-piszczelowego. Podkreśla się rolę ćwiczeń trójpłaszczyznowych, ekscentrycznych, wywołujących rotację miednicy podczas ćwiczeń. Po 7 tygodniach stosowania agresywnej, funkcjonalnej rehabilitacji zawodnik wznowił treningi specjalistyczne bez bólu i zaburzeń funkcjonalnych.

Wnioski: Wczesna diagnoza ITBS pozwala na skrócenie czasu leczenia rehabilitacyjnego. Konieczne jest wykrycie zaburzeń biomechanicznych, które przyczyniły się do powstania ITBS. 7-tygodniowa rehabilitacja, z zastosowaniem trójpłaszczyznowych ćwiczeń funkcjonalnych jest skuteczną metodą leczenia ITBS. Zaleca się kontynuację stosowania ćwiczeń przez okres 6-12 miesięcy w celu zmniejszenia ryzyka nawrotu kontuzji.

Słowa kluczowe:

pasmo biodrowo-piszczelowe, kontuzja przeciążeniowa, mięsień pośladkowy średni, trójpłaszczyznowy trening ekscentryczny

\section{Summary}

Introduction: „Runner's knee”, in other words Iliotibial Band Syndrome (ITBS) is the second, after PFPS, in terms of incidence frequency overuse injury amongst runners $-8.5 \%$. It is the most common cause of lateral knee pain. It mainly occurs in middle aged athletes, in the second decade of life. Cyclists, skiers, weight lifters, soccer and tennis players are next groups, where this clinical entity occurs. ITBS is typical overuse injury which results from 
cyclic friction (or compression) of iliotibial band on lateral epicondyle of femur. Training errors are main risk factors. Biomechanical disorders leading to this entity are: weakness of gluteus medius, lack of functional hip mobility, weakness of knee flexors and extensors, shortness of hip adductors, limited hip internal rotation. Improper saddle height, frame size or incorrect pedal position can cause ITBS among cyclists.

Case study: Professional cyclist was referred to Rehabilitation Centre, complaining about severe pain located at lateral side of the right knee, lasting from 4 months. The pain was described as burning, sharp, increasing during biking, finally disabling him to continue sports activity. After biomechanical analysis we introduced functional re-education training correcting disbalances, the causes of injury. The role of tri-planar, eccentric exercises rotating the pelvis is underlined. After 7 weeks of aggressive, functional rehabilitation resumed sports activity without pain and functional limitations.

Conclusions: An early diagnosis of ITBS allows for shorter rehabilitation time. It's necessary to precisely determine biomechanical disorders leading to ITBS. 7-week rehabilitation, with functional, three dimensional exercises is effective mean of ITBS treatment. We recommend to continue this kind of exercises for 6-12 months to prevent injury recurrence.

\section{Keywords: $\quad$ iliotibial band, overuse injury, gluteus medius, triplanar eccentric training}

\section{Wstęp}

Zespół pasma biodrowo-piszczelowego jest najczęstszą przyczyna bólu bocznego przedziału stawu kolanowego wśród osób biegających $[1,2,3,4,5]$ i drugą, po PFPS, pod względem częstotliwości występowania kontuzją przeciążeniową - 8.5\% [6]. „Kolano biegacza”, inaczej zespół pasma biodrowo-piszczelowego (ITBS), opisany został jako jednostka kliniczna pierwszy raz przez Renne w 1975 roku. Występuje u zawodników w średnim wieku, w drugiej dekadzie życia. Kolarze, narciarze, ciężarowcy, piłkarze nożni, tenisiści, to kolejne grupy sportowców, u których notuje się występowanie tej jednostki $[7,8,9]$. Częste, powtarzające się tarcie pasma biodrowo-piszczelowego o nadkłykieć boczny kości udowej jest powodem powstania ITBS. Pasmo to przesuwa się ku przodowi w momencie czynności wyprostu w stawie kolanowym i ku tyłowi podczas zginania w stawie kolanowym, pozostając przez cały czas W napięciu [10].

Anatomia i biomechanika. Pasmo biodrowo-piszczelowe (ITB) jest silnym, ścięgnistym pasmem, będącym kontynuacją mięśnia naprężacza powięzi szerokiej (TFL), mięśnia pośladkowego średniego i wielkiego [11]. Dolne przyczepy zlokalizowane są na guzku Gerdy’ego, głowie kości strzałkowej i wplatają się w troczki boczne i brzeg boczny rzepki $[12,13]$. TFL ma kształt paska, mającego początkowy przyczep tuż za kolcem biodrowym przednim (ASIS) i przyczepia się do ITB. Wymienione mięśnie odpowiedzialne są za kontrolę odwiedzenia w stawie biodrowym, ekscentrycznie rozciaggają się podczas fazy podporu [14], oraz kontrolują wyprost w stawie biodrowym i kolanowym [8]. Ponadto uznaje się, że tylny komponent mięśnia pośladkowego średniego i całość mięśnia pośladkowego małego odpowiadają za stabilizację głowy kości udowej w panewce podczas fazy podporu chodu [15]. Badania biomechaniczne wykazały, że tylne włókna ITB wchodzą w konflikt $\mathrm{z}$ nadkłykciem bocznym kości udowej w momencie kontaktu początkowego pięty z podłożem, średnio w kącie $21,4^{\circ} \pm 4,3^{\circ}$ zgięcia w stawie kolanowym [16]. Cykliczne, powtarzające się tarcie może prowadzić do przewlekłego stanu zapalnego, głównie pod tylnymi włóknami ITB, które uważa się, że są mniej elastyczne od przednich [14].

Etiologia. Uznaje się, że błędy treningowe są podstawowym czynnikiem ryzyka ITBS, z których na pierwszym miejscu jest długotrwały bieg w tym samym kierunku po bieżni i bieg w dół [14]. Osłabienie mięśnia pośladkowego średniego, ograniczenie funkcjonalnej ruchomości w stawie biodrowym [11], osłabienie mięśni zginających i prostujących w stawie kolanowym [17], przykurcz mięśni przywodzących w stawie biodrowym, przykurcz rotacji wewnętrznej w stawie biodrowym [18], to kolejne czynniki ryzyka. U kolarzy, ITBS może wynikać z nieprawidłowego ustawienia wysokości siodełka, niewłaściwie dobranego rozmiaru ramy lub nieprawidłowej pozycji pedałów [19].

Symptomy. Ból, często palący, kłujący, promieniujący ku dołowi, pojawia się zazwyczaj po wysiłku fizycznym. Zlokalizowany jest tuż nad nadkłykciem bocznym kości udowej, 2-3 cm ponad linią stawową. Krepitacja lub obrzęk mogą występować wokół bolesnego obszaru. Trening przez ból spowoduje zintensyfikowanie objawów i zwiększy ryzyko powstania kontuzji przewlekłej [14].

Badanie kliniczne. Podstawowym testem służącym do diagnozy klinicznej jest test Noble'a [7]. Pacjent leży na boku, z kończyną testowaną na górze, zgiętą w stawie kolanowym do kata $90^{\circ}$. Terapeuta stosuje nacisk na nadkłykieć boczny lub 1-2 cm powyżej (ryc. 1). Ból pojawiający się podczas prostowania kończyny w stawie kolanowym, w kącie $30^{\circ}$, świadczy o ITBS. 


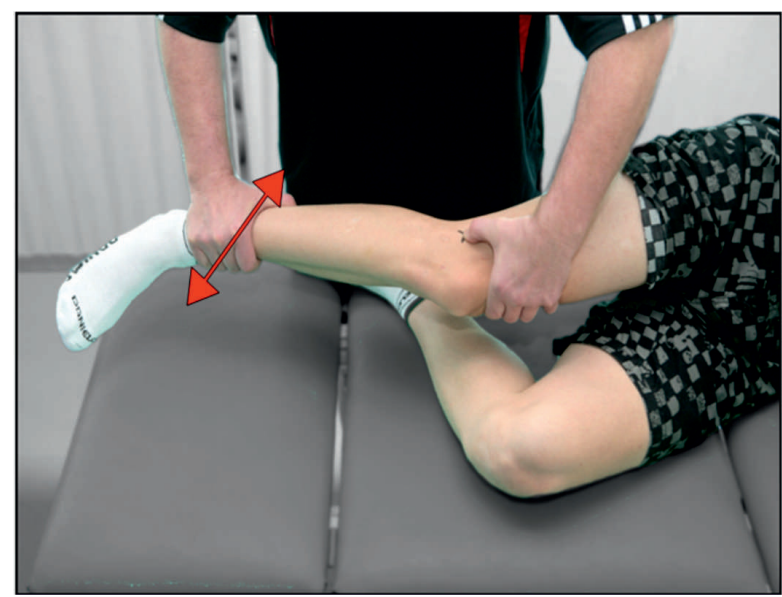

Ryc. 1. Test Noble'a

Fig. 1. Noble test

Dodatkowymi, pomocniczymi testami są: test Thomasa i Obera, służące do oceny elastyczności mięśnia lędźwiowego, prostego uda i pasma biodrowo-piszczelowego [20]. Ważna jest również ocena elastyczności mięśnia brzuchatego łydki i płaszczkowatego, supinacji i pronacji stopy oraz rotacji podudzia [14].

W przypadku jasnej, bezdyskusyjnej diagnozy obrazowanie radiologiczne wydaje się zbędne [14].

\section{Opis przypadku}

Do Centrum Rehabilitacji Ruchowej zgłosił się zawodnik, czynnie uprawiający kolarstwo, skarżący się na ból w bocznej okolicy stawu kolanowego prawego. Ból trwał od 4 miesięcy. Chory opisywał go jako uporczywy, piekący, narastający podczas intensywnej jazdy na rowerze, w efekcie końcowym uniemożliwiający kontynuowanie aktywności fizycznej. Zawodnik nadmienił o wskazówkach trenerskich nakazujących podczas jazdy na rowerze kierowanie kolan przyśrodkowo.

Postępowanie lecznicze. Podstawowym celem postępowania leczniczego $\mathrm{w}$ fazie ostrej jest wyciszenie stanu zapalnego poprzez modyfikację aktywności fizycznej, stosowanie chłodzących okładów, aplikację niesterydowych leków przeciwzapalnych oraz rozciąganie pasma biodrowo-piszczelowego [19,21]. Niektórzy autorzy zalecają stosowanie zabiegów fizykalnych typu ultradźwięki [22]. W przypadku przedłużającego się bólu i stanu zapalnego rekomenduje się iniekcje sterydowe [23].

$\mathrm{Na}$ podstawie badań biomechanicznych uznaje się dzisiaj jako najbardziej skuteczne rozciaganie pasma biodrowego w pozycji stojącej, z kończyną chorą, jako zakroczną, wyprostowaną i przywiedzioną w stawie biodrowym [11,14]. Zawodnik, z rękoma splecionymi nad głową, wykonuje skłon diagonalnie w kierunku kończyny kontralateralnej (ryc. 2).

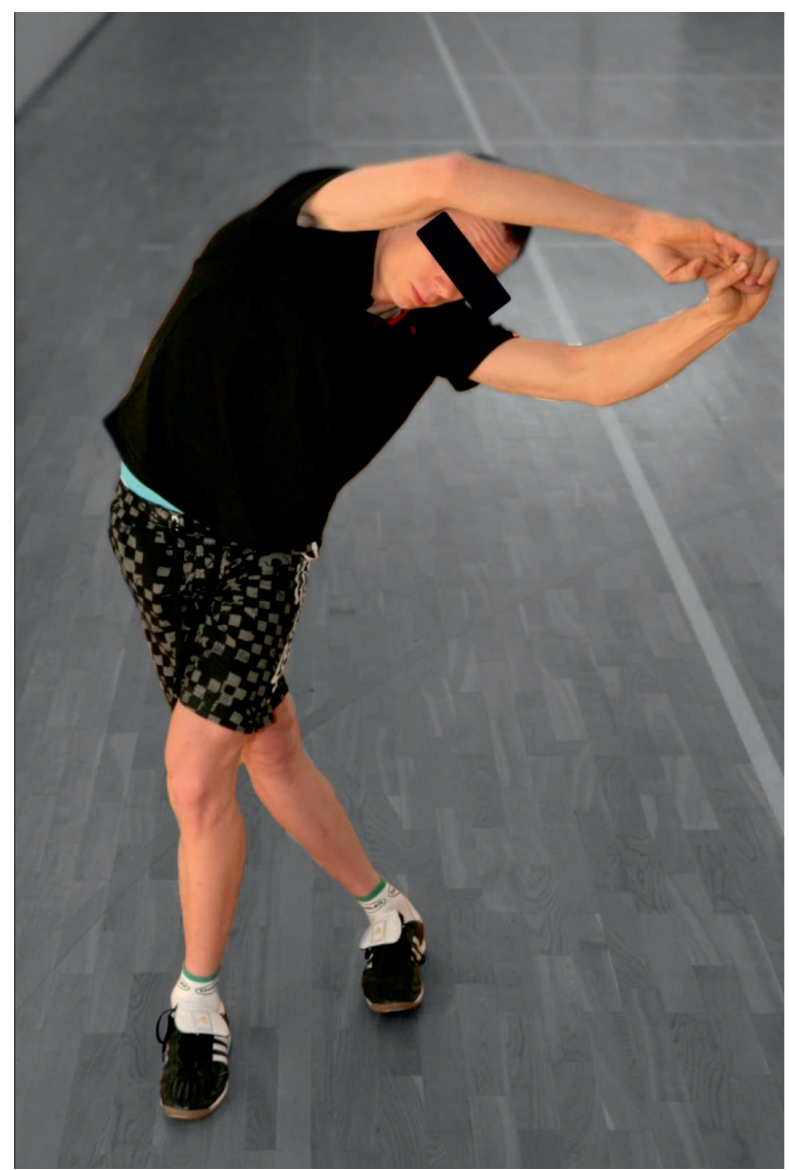

Ryc. 2. Rozciaganie pasma biodrowo-piszczelowego

Fig. 2. Stretching iliotibial band

Konieczne jest też stosowanie masażu tkanek miękkich (STM), z uwzględnieniem punktów spustowych oraz zrostów powięziowych na paśmie biodrowo-piszczelowym, pośladkowym średnim czy grupie tylnej mięśni uda [21]. Pomocny i skuteczny jest automasaż na rolce [24] (ryc. 3, 4).

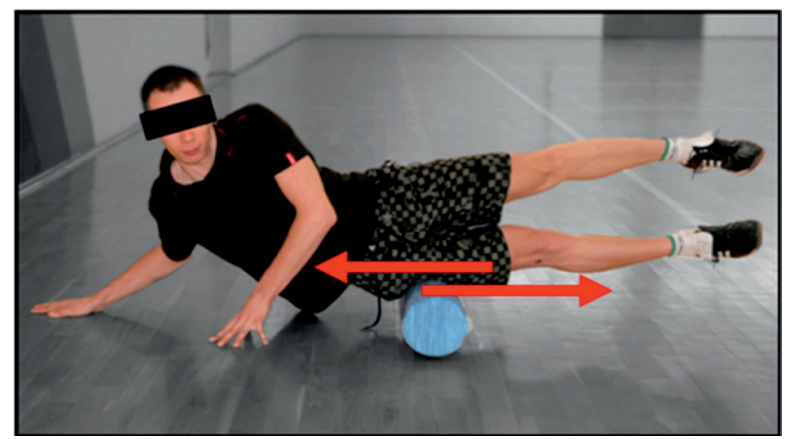

Ryc. 3. Automasaż pasma biodrowo-piszczelowego na rolce

Fig. 3. Automassage of IT band on roll 


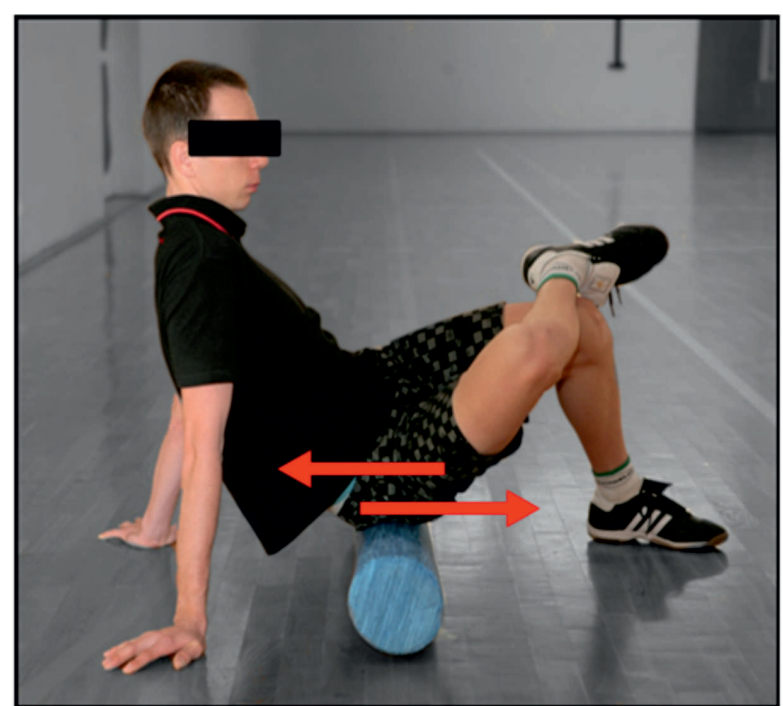

Ryc. 4. Automasaż mięśnia pośladkowego średniego i mięśnia gruszkowatego na rolce

Fig. 4. Automassage of gluteus medius and piriformis on roll

Kolejnym krokiem jest zastosowanie funkcjonalnego, wielotorowego treningu reedukacji [17], mającego na celu eliminację zaburzeń biomechanicznych, będących powodem powstania zespołu pasma biodrowo-piszczelowego. Fredericson (2005) podkreśla rolę ćwiczeń trójpłaszczyznowych, ekscentrycznych, wywołujących rotację miednicy podczas ćwiczeń. Uznaje się za podstawowy cel wzmocnienie, uaktywnienie mięśnia pośladkowego średniego, z jednoczesnym wyciszeniem aktywności mięśnia naprężacza powięzi szerokiej (ryc. 5, 6, 7, 8). Dodatkowo stosuje się funkcjonalne ćwiczenia grupy tylnej mięśni uda (ryc. 9, 10).

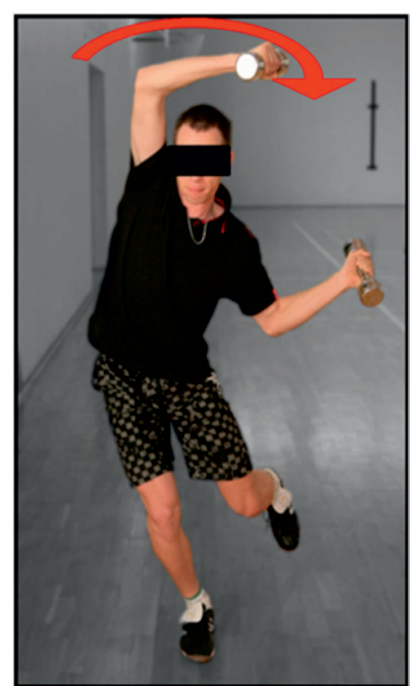

Ryc. 5. Ćwiczenie ekscentryczne mięśnia pośladkowego średniego

Fig. 5. Eccentric exercise of gluteus medius

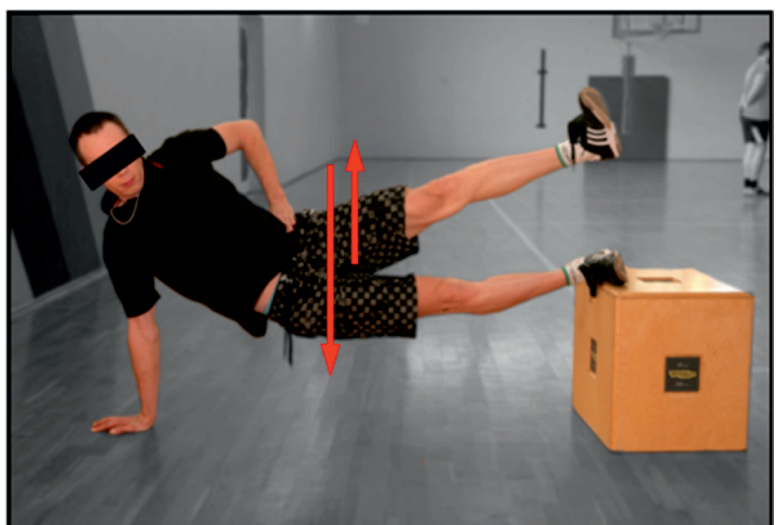

Ryc. 6. Ćwiczenie ekscentryczne mięśnia pośladkowego średniego

Fig. 6. Eccentric exercise of gluteus medius

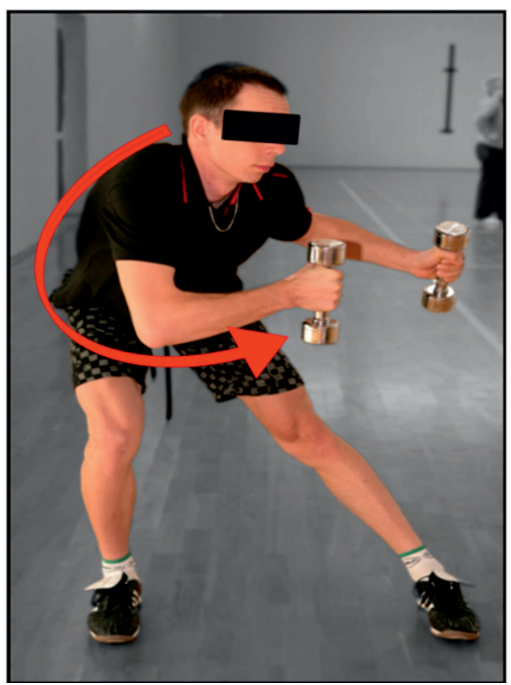

Ryc. 7. Przysiad boczny z rotacją tułowia

Fig. 7. Side squat with trunk rotation

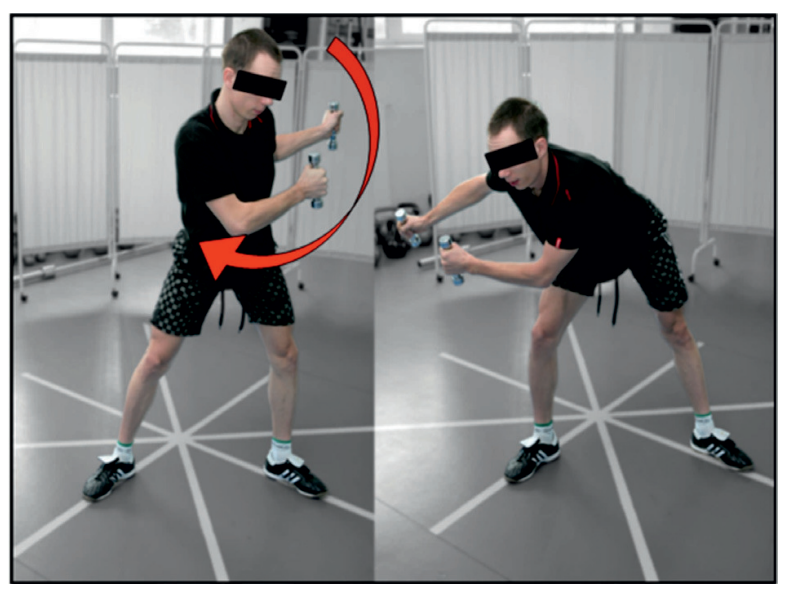

Ryc. 8. Ćwiczenie trójpłaszczyznowe, rotacyjne mięśnia pośladkowego średniego

Fig. 8. Three dimensional exercise of gluteus medius 


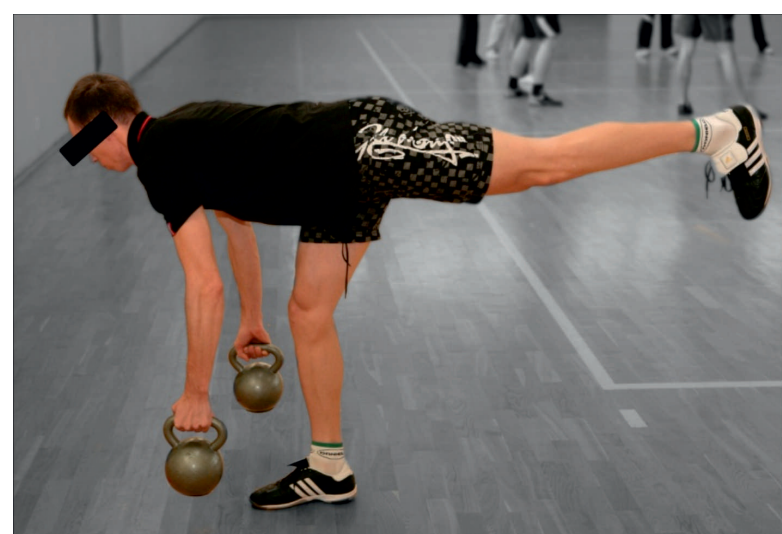

Ryc. 9. Ćwiczenie funkcjonalne grupy tylnej mięśni uda (tzw. hip hinge)

Fig. 9. Functional exercise of hamstring muscle (hip hinge)

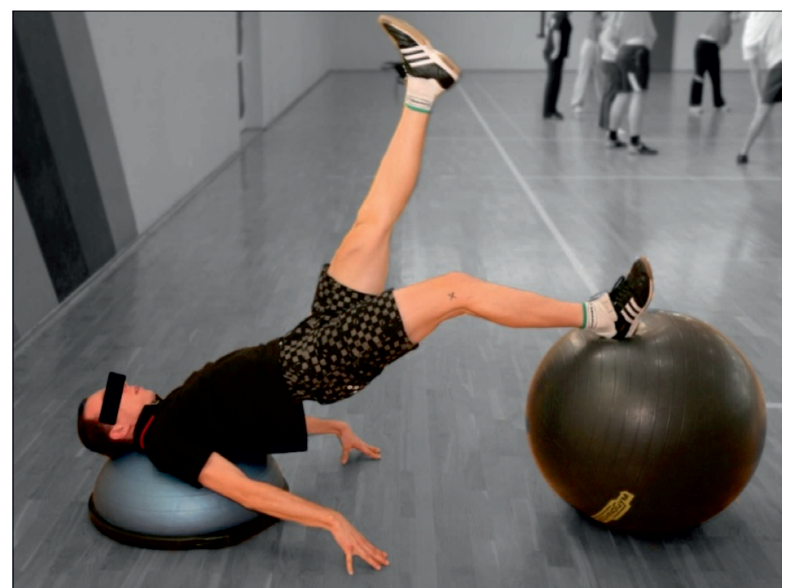

Ryc. 10. Ćwiczenie funkcjonalne grupy tylnej mięśni uda (tzw. bridge)

Fig. 10. Functional exercise of hamstring muscles (bridge)

Po 7 tygodniach stosowania agresywnej, funkcjonalnej rehabilitacji zawodnik wznowił treningi specjalistyczne bez bólu i zaburzeń funkcjonalnych. W trakcie trwania rehabilitacji przy wykorzystaniu piłek stabilizacyjnych, BOSU, Terapii Master, kettlebells i hantli zastosowaliśmy około 60 różnorodnych ćwiczeń funkcjonalnych. Wzięliśmy pod uwagę specyfikę jazdy na rowerze, podczas której mięśnie stabilizacyjne łopatek, tułowia i miednicy są angażowane w małym stopniu, w związku z tym wymagają ćwiczeń o charakterze prewencyjnym. Zawodnik poinstruowany został o konieczności kontynuowania ćwiczeń funkcjonalnych, z naciskiem na ćwiczenia ekscentryczne mięśnia pośladkowego średniego przy wyprostowanej kończynie w stawie biodrowym, w zamkniętym łańcuchu kinematycznym. Takie podejście konieczne jest ze względu na upośledzoną pracę tego mięśnia podczas jazdy na rowerze, ze zgiętą kończyną w stawie biodrowym [25]. Dodatkową wskazów- ką było unikanie kierowania kolan do środka podczas jazdy na rowerze. Takie ustawienie kończyny powoduje wewnętrzną rotację w stawie biodrowym i wzmożone napięcie ITB, i może być powodem nawrotu zespołu pasma biodrowo-piszczelowego.

Kompleksowe, agresywne postępowanie rehabilitacyjne zastosowane u zawodnika z ITBS okazało się skuteczną terapią, pozwalająca na optymalnie szybkie wznowienie treningów sportowych bez bólu i zaburzeń funkcjonalnych. Jest to zgodne z wcześniejszymi doniesieniami [14]. Podkreśla się rolę szerszego podejścia do leczenia niż tylko standardową, przeciwzapalną strategię i rozciaganie pasma biodro-piszczelowego. Ważne jest biomechaniczne podejście do zaburzeń, które pozwala na korektę zaburzeń mięsni rotujących zewnętrznie w stawie biodrowym i jednocześnie odpowiadających za czynnościowe ustawienie stawu kolanowego. Poprzez zastosowanie trójpłaszczyznowych, ekscentrycznych ćwiczeń udało się odtworzyć prawidłowe wzorce ruchowe i kontrolę nerwowo-mięśniową nad ruchem.

\section{Wnioski}

Wczesna diagnoza ITBS pozwala na skrócenie czasu leczenia rehabilitacyjnego. Konieczne jest wykrycie zaburzeń biomechanicznych, które przyczyniły się do powstania ITBS. 7-tygodniowa rehabilitacja, z zastosowaniem trójpłaszczyznowych ćwiczeń funkcjonalnych jest skuteczną metodą leczenia ITBS. Zaleca się kontynuację stosowania ćwiczeń przez okres 6-12 miesięcy w celu utrwalenia wzorców ruchowych i zmniejszenia ryzyka nawrotu kontuzji. Po 2 latach od momentu zakończenia procesu rehabilitacyjnego zawodnika kontrola wykazała brak bólu i zaburzeń funkcjonalnych typowych dla ITBS.

\section{Piśmiennictwo}

1. Barber FA, Sutker AN. Iliotibial band syndrome. Sports Med1992; 14(2): 144-8.

2. Clement DB, Taunton JE, Smart GW, et al. A survey of overuse running injuries. Phys Sportsmed 1981; 9(5): 4758.

3. Linderburg G, Pinshaw R, Noakes TD. Iliotibial band syndrome in runners. Phys Sportsmed 1984; 12(5): 118-30.

4. Noble CA. Iliotibial band friction syndrome in runners. Sports Med 1980 Jul-Aug; 8(4): 232-4.

5. Fredericson M, Weir A. Practical management of iliotibial band syndrome in runners. Clin J Sports Med 2006; 16(3): 261-8.

6. Taunton JE, Ryan MB, Clement DB. A retrospective case-control analysis of 2002 running injuries. Br J Sports Med 2002; 36: 95-101.

7. Noble CA. The treatment of iliotibial band friction syndrome. Br J Sports Med 1979; 13: 51-54. 
8. Lucas CA. Iliotibial Band Friction Syndrome as Exhibited in Athletes. Journal of Athletic Training 1992; 27(3): 250252.

9. Kirk KL, Kuklo T, Klemme W. Iliotibial band friction syndrome. Orthopedics 2000; 23(11): 1209-14.

10. Evans P. The postural function of the iliotibial tract. Ann R Coll Surg Engl 1979; 61(4): 271-80.

11. Paluska SA. An Overview of Hip Injuries in Running. Sports Med 2005; 35(11): 991-1014.

12. Terry GC, Hughston JC, Norwood LA. The anatomy of the iliopatellar band and iliotibial tract. Am J Sports Med 1986; 14(1): 39-45.

13. Martens M, Libbrecht P, Burssens A. Surgical treatment of iliotibial band friction syndrome. Am J Sports Med 1989; 17(5): 651-4.

14. Fredericson M, Wolf C. Iliotibial band syndrome in runners: innovations in treatment. Sports Med 2005; 35(5): 451-9.

15. Gottschalk F, Kourosh S, Leveau B. The functional anatomy of tensor fascia latae and gluteus medius and minimus. J Anat 1989; 166: 179-89.

16. Orchard JW, Fricker PA, Abud AT. Biomechanics of Iliotibial band friction syndrome in runners. American Journal of Sports Medicine 1996; 24(3): 375-9.

17. Pettitt R, Dolski A. Corrective Neuromuscular Approach to the Treatment of Iliotibial Band Friction Syndrome:
A Case Report. Journal of Athletic Training 2000; 35(1): 96-99.

18. Noehren B, Davis I, Hamill J. ASB clinical biomechanics award winner 2006 prospective study of the biomechanical factors associated with iliotibial band syndrome. Clin Biomech 2007; 22(9): 951-6.

19. Cosca DD, Navazio F. Common Problems in Endurance Athletes. American Family Physician 2007; 15: 237-246.

20. Harvey D. Assessment of the flexibility of elite athletes using the modified Thomas test. Br J Sports Med 1998; 32: $68-70$.

21. Ellis R, Hing W, Reid D. Iliotibial band friction syndrome - a systematic review 2007; 12(3): 200-8.

22. Pedowitz RN. Use of Osteopathic for Iliotibial Band Friction Syndrome. The Journal of the American Osteopathic Association 2005; 105(12): 563-567.

23. Gunter P, Scwellnus MP. Local corticosteroid injection in iliotibial band friction syndrome in runners: a randomized controlled trial. Br J Sports Med 2004; 38: 269-272.

24. Fredericson M, Guillet M, DeBenedictis L. Quick Solution for Iliotibial Band Syndrome. The Physician and Sports Medicine 2000; 28(2): 53-68.

25. Oatis CA. Kinesiology. The Mechanics and Pathomechanics of Human Movement. Lippincott Williams \& Wilkins; 2004. p.688-9. 